\title{
Musicae Scientiae
}

http://msx.sagepub.com/

The arousing and cathartic effects of popular heartbreak songs as revealed in the physiological responses of listeners

Chen-Gia Tsai, Rong-Shan Chen and Tzung-Shian Tsai

Musicae Scientiae 2014 18: 410 originally published online 15 July 2014

DOI: $10.1177 / 1029864914542671$

The online version of this article can be found at:

http://msx.sagepub.com/content/18/4/410

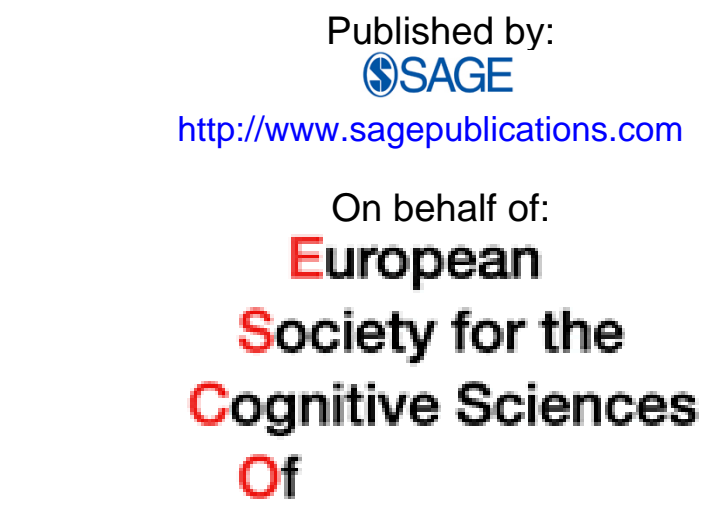

\section{Music}

European Society for the Cognitive Sciences of Music

Additional services and information for Musicae Scientiae can be found at:

Email Alerts: http://msx.sagepub.com/cgi/alerts

Subscriptions: http://msx.sagepub.com/subscriptions

Reprints: http://www.sagepub.com/journalsReprints.nav

Permissions: http://www.sagepub.com/journalsPermissions.nav

Citations: http://msx.sagepub.com/content/18/4/410.refs.html

>> Version of Record - Nov 4, 2014

OnlineFirst Version of Record - Jul 15, 2014 


\title{
The arousing and cathartic effects of popular heartbreak songs as revealed in the physiological responses of listeners
}

Musicae Scientiae 2014, Vol. 18(4) 410-422 (C) The Author(s) 2014

Reprints and permissions: sagepub.co.uk/journalsPermissions.nav DOI: $10.1 \mid$ |77/I0298649|454267| msx.sagepub.com

@SAGE

\section{Chen-Gia Tsai}

National Taiwan University, Taiwan

\section{Rong-Shan Chen}

National Taiwan University, Taiwan

\section{Tzung-Shian Tsai}

National Taiwan University, Taiwan

\begin{abstract}
Songs that convey sorrowful emotions enjoy widespread popularity. The expressions and effects of negative emotions vary considerably across cultures and musical forms. This study explores the physiological responses to five popular "heartbreak" songs, focusing on the relationships between the temporal dynamics of emotion and the verse-chorus form. Listeners' skin conductance and finger temperature were used to infer levels of arousal and relaxation, and the analysis of these time-series data was guided by a priori knowledge of the musical form. We found that two particular time periods in these songs, the passage preceding the chorus and the entrance of the chorus, evoked significant skin conductance responses. Given that the chorus is usually the most favorite element of a popular song, these two responses may reflect the elevated arousal associated with the feelings of "wanting" and "liking", respectively. Moreover, the average finger temperature exhibited a U-shaped curve across each song. The significant decreases of finger temperature within the first part of songs revealed an accumulation of negative emotions in listeners, whereas the significant increases of finger temperature within the second part may reflect a release, resolution, or regulation of negative emotions. Our findings shed new light on the rewarding nature of the chorus and the cathartic effects associated with the versechorus form of heartbreak songs.
\end{abstract}

\section{Keywords}

finger temperature, music and emotion, relaxation, skin conductance, verse-chorus form 


\section{Introduction}

Music conveys a broad range of human emotions, including negative emotions. Compared to happy music, bittersweet sadness songs generally evoke more reports of emotional peak experience (Panksepp \& Bernatzky, 2002). Various disciplines have addressed the question of why negatively valenced music enjoys widespread popularity. Panksepp and Bernatzky (2002) proposed the separation-call theory of sad music, which claims that chill-inducing sad music contains acoustic properties similar to the separation call of young animals, namely, "the primal cry of despair to signal caretakers to exhibit social care and attention". Given the distinction between music-induced emotions and music-expressed emotions, it was found that listening to sad music induced stronger romantic and blithe emotions as compared to the emotions perceived in the same music (Kawakami, Furukawa, Katahira, \& Okanoya, 2013). Further, when individuals experience distress from weakened or broken interpersonal relationships, listening to sad music may offer a sense of emotional sharing, akin to interacting with an empathetic friend (Lee, Andrade, Palmer, 2013). From a physiological view point, the prolactin-oxytocin system that mediates social bonding and affiliation may play a role in individual responses to sad music (Chanda \& Levitin, 2013; Huron, 2011).

While individual differences in personality traits, experiences and mood states have been found to influence emotional response to sad music (Garrido \& Schubert, 2011; Wilhelm, Gillis, Schubert, \& Whittle, 2013), it is important to note that the musical expressions and effects of negative emotions vary considerably across cultures and musical forms. In East Asia, for example, a majority of popular songs deal with the topic of pain and heartbreak caused by romantic relationships (Shaw \& Su, 2001; Shin \& Oh, 2002; Stevens, 2007). These popular songs typically employ a verse-chorus form. In this form, the chorus contrasts with the preceding verse (or the preceding transition: pre-chorus) in terms of elevated intensity, which is achieved through changes in lyrical content, sound level, pitch level, rhythmic/textual activity, and/or timbral noise (Capuzzo, 2009; Doll, 2011). Further, the chorus, interspersed between the narrative verses, usually presents the musical climax and the lyrical point of a song (Davis, 1984). While the verse of a heartbreak song often depicts static (natural or social) scenes or the current status of an interpersonal relationship, the chorus often conveys the singer's inner sorrow or passions (Tsai, Chen, \& Yu, in press). The verse-chorus progression in heartbreak songs may provide listeners an outlet for their own negative emotions and facilitate a cathartic release.

The moving power of a song unfolds over time, and the musical form plays a critical role in listeners' emotional-cognitive processes. Rolison and Edworthy (2012) used unfamiliar versechorus songs to test the salience of this formal structure by asking participants to identify the likely positions of the 8 sections that comprise the "verse-chorus-bridge form" (Stephenson, 2002). These sections include Intro, Verse 1, Chorus 1, Verse 2, Chorus 2, Bridge (solo), Chorus 3, and Extro. Participants were relatively successful in placing sections in their proper location. This result suggests that listeners have implicit knowledge of song structure and of the different characteristics/functions of song sections. The verse and chorus acquire their hierarchical importance and emotional significance by means of placement, contrast, and repetition.

To date, little is known about the relationships between the musical form and the temporal dynamics of emotion. It remains an empirical question as to how the arrangement of musical sections promotes emotional experiences. The present study brings into focus the extent to which the verse-chorus form of heartbreak songs affects physiological reactions in listeners. Regarding the key role of the chorus in a popular song, we hypothesized that the level of listener's arousal reaches its local maximum at the start of the chorus, even when negative emotions are conveyed. Furthermore, we hypothesized that the first verse-chorus progression 
facilitates the venting of negative emotions in listeners and that listeners thus may feel more relaxed after the end of the first chorus. Following previous studies on synchronicity between physiological responses and musical events (e.g., Grewe, Nagel, Kopiez, \& Altenmüller, 2007a; Guhn, Hamm, \& Zentner, 2007), this study employed physiological measures to assess the time course of emotions. Skin conductance and finger temperature were used to assess the levels of arousal and relaxation, respectively. There is a high correlation between sympathetic nerve activity and skin conductance response (SCR) (Lang, Greenwald, Bradley, \& Hamm, 1993; Wallin, 1981). Several studies have recommended skin conductance as a highly sensitive measure of music-induced arousal (Craig, 2005; Grewe et al., 2007a; Khalfa, Isabelle, Jean-Pierre, \& Manon, 2002; Rickard, 2004). Previous studies have also identified related variance in finger temperature to the emotion valence of music (Mcfarland, 1985), with happy or relaxing music tending to increase the finger temperature of listeners (Hsu \& Lai, 2004; Lai, 2004; Lundqvist, Carlsson, Hilmersson, \& Juslin, 2009; Rickard, 2004), and sad or fear-inducing music tending to decrease finger temperature (Krumhansl, 1997; Nater, Abbruzzese, Krebs, \& Ehlert, 2006). Clinics have employed hand-warming biofeedback as an adjunct to relaxation training, suggesting that higher temperatures may be associated with relaxation as blood vessels dilate, whereas lower temperatures may be associated with stress as blood vessels constrict (Penzien \& Holroyd, 1994).

The aim of the current study is twofold. First, using SCR amplitude as the index of sympathetic arousal, we expected to demonstrate that listeners experience their highest arousal levels shortly before and at the beginning of the chorus of heartbreak songs. Recently, Salimpoor and colleagues reported that the "wanting" phase (the anticipatory phase of reward) and the "liking" phase (the consummatory phase of reward) during a musical listening experience were associated with anatomically distinct activity in the brain's reward system (Salimpoor, Benovoy, Larcher, Dagher, \& Zatorre, 2011). In popular music, the chorus may be thought of as "rewards" for listening. We hypothesized that the passage immediately before the chorus and the chorus entrance may evoke intense feelings of "wanting" and "liking", respectively. These intense feelings may be reflected by SCRs.

Second, using finger temperature as the index of relaxation level, we expected to demonstrate that the finger temperature of listeners creates a "U-shaped" plot as heartbreak songs play from start to finish. We hypothesized that the intro and the first verse-chorus progression of heartbreak songs may intensify the negative emotions of listeners, and thereby their finger temperature may decrease. The remaining parts of these songs may lead to a release, resolution, or regulation of negative emotions in listeners, and thereby their finger temperature may increase. Results from this inquiry promised to deepen our knowledge of the complicated relationships between the musical form and the temporal dynamics of emotion.

\section{Methods}

\section{Participants}

Thirty-nine volunteers ( 18 females, 21 males, $M_{\text {age }}=22.5$ years, $S D=1.6$ ) were recruited as participants. Recruitment methods included an online advertisement and an announcement delivered in undergraduate-level music courses. The recruitment message asked that respondents have a high familiarity with popular Mandarin-language songs. All participants reported having no neurological, mental, or hearing problems. Written informed consent was obtained from each participant prior to participation in the study. After the experiment, each participant received monetary compensation for their participation. 


\section{Stimuli}

Five Mandarin-language songs currently popular in Taiwan were used as stimuli, including Adoration, Lost Shoal, Give Me a Reason to Forget, Onion, and Listen to the Sea. Each song had been viewed more than two million times on YouTube (as of October, 2011). Their lyrics talk about love, isolation, and heartbreak. Each song was in the verse-chorus form, with the chorus conveying increasing levels of emotional and musical intensity. Four of the five songs were in the verse-chorus-bridge form and thus contained a bridge immediately prior to the third chorus. The fifth song incorporated only two alternations of the verse and the chorus. Song tempos

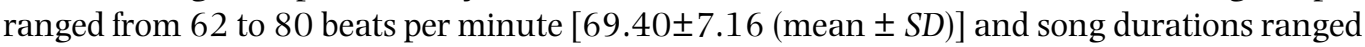
from 04:00 to 05:36. All musical stimuli were converted into digital (44,100 Hz sampling rate, 16 bit stereo) WAV files from the original CD recordings. The intensity of all musical stimuli was roughly normalized and the maximum sound level was controlled to approximately $70 \mathrm{~dB}$.

\section{Procedure}

Participants reclined in a comfortable armchair in a sound-attenuated room with ambient temperature between $20^{\circ} \mathrm{C}$ and $27^{\circ} \mathrm{C}$. During the listening session, the five songs were presented in random order through two speakers that were set in front of the chair. The presentation of each song was preceded by a 10-second silence, a warning tone $(600 \mathrm{~Hz}, 100 \mathrm{~ms})$, and another 5-second silence. The participants were asked to read printed lyrics of the song while listening to maximize listening comprehension. After the presentation of each song, the participants were asked to rate their preference, familiarity, and "urge to cry" on a 7-point scale ranging from "not at all" (1) to "extreme" (7). Scores were used to assess the popularity and the "heartbreak" quality of each song. Participants spent approximately 40 minutes to complete the experiment.

\section{Measurements}

Three physiological measures were obtained using a Biopac MP35 system (Biopac Systems Inc., USA), including skin conductance, finger temperature, and respiration. Skin conductance was recorded by placing electrodes on volar surfaces of the medial phalanges of the forefinger and the middle finger of the non-dominant hand. A skin conductance finger transducer filled with an isotonic conducting gel was used. Finger temperature was recorded by placing a temperature probe on volar surfaces of the medial phalanges of the ring finger on the nondominant hand. Respiration was assessed via a belt placed on the chest that contained a piezoelectric sensor responsive to changes in thoracic circumference. Data on respiration is not presented in this paper.

\section{Data processing}

Data processing and statistical analysis were carried out using self-developed programs implemented in Matlab (Matlab Inc., USA). First, raw data on skin conductance was smoothed using a fourth-order Butterworth low-pass filter with a cutoff frequency of $3 \mathrm{~Hz}$, and then downsampled to $10 \mathrm{~Hz}$ by averaging. The amplitude of SCR was calculated in terms of the SCR slope, which has been found to be a good predictor of arousal (Azadeh, Jillian, Satyam, Gillian, \& Tom, 2011; Blain, Mihailidis, \& Chau, 2008; Blain, Power, Sejdic, Mihailidis, \& Chau, 2010). Because the accumulation of an electrical charge at the electrode-skin junction may cause a linear 
decrease in skin conductance (Salimpoor, Benovoy, Longo, Cooperstock, \& Zatorre, 2009), negative values of the SCR slope were set to zero. A 3-second moving time window was used to extract SCR amplitude at each point of time, with SCR amplitude at the midpoint of this time window being the integral of the SCR slope (summation of SCR slope within the window divided by the sampling rate $10 \mathrm{~Hz}$ ).

The data of finger temperature were downsampled to $10 \mathrm{~Hz}$ by averaging. We hypothesized that the time courses for mean finger temperature would be approximately U-shaped, with finger temperature tending to decrease from the onset of a song to the end of its first chorus (1st part) and then to increase thereafter (2nd part). The changes in individual finger temperature over the first part and the second part of each song were thus calculated. For each participant, we averaged the temperature changes of five songs and obtained the mean temperature changes of the first part and second part of songs.

\section{Statistical analysis}

Analysis of physiological signals was performed under the guidance of musical form. A temporal "region of interest" (ROI) was selected at the entrances of the first and second choruses of each song, as the target region for assessing elevated arousal. Defining the first downbeat of a chorus as $t=0$, we confined our ROI in the time span of $t=-8$ to $t=10$. For each time points in ROI, the values of SCR amplitude across all participants and all verses/choruses were pooled. Peaks on the median curve of pooled SCR amplitude were identified by and compared to the control condition. One-tail tests were used to examine whether the peaks of SCR amplitude were significantly higher than the control data.

We assumed that the arousing effects of verse-chorus songs may be achieved by using greater musical and emotional intensity during the chorus than during the verse. Therefore, the first verse of each song was designated as the control condition for statistical analysis of SCR amplitude. The time courses of SCR amplitude were downsampled to $1 / 3 \mathrm{~Hz}$, and then the values of SCR amplitude of all participants within the five verses were pooled as the control data. This downsampling was performed because the time window for of SCR amplitude extraction was 3 seconds in duration. Because of the non-normality of the distribution of the SCR amplitude, a Wilcoxon rank sum test was performed for each two peaks of the SCR median curve within ROI. These tests examined the SCR amplitude data at the peaks relative to the control data.

For the data of finger temperature, we compared the temperature changes of the first part and the second part of songs to the zero degree point using one-sample $t$-tests. One-tailed $t$-tests were performed to reveal (1) whether the finger temperature significantly decreased over the first part of songs, and (2) whether the finger temperature significantly increased over the second part of songs. For all statistical tests in this study, the criterion for significance was set to $\alpha=.05$.

\section{Results}

Results of song rating are given in Table 1 . As the table shows, participants generally gave moderate to high scores for preference, familiarity, and urge to cry. These scores provide evidence for the popularity and for the heartbreaking character of the musical stimuli.

Figure 1 shows the median curve of SCR amplitude, with two peaks at $t_{1}=-0.4 \mathrm{~s}$ and $\mathrm{t}_{2}=5.4$ s. Wilcoxon rank sum tests revealed that these peaks were significantly larger than the control data $\left(\mathrm{t}_{1}=-0.4 \mathrm{~s}, z=3.46, p<.001 ; \mathrm{t}_{2}=5.4 \mathrm{~s}, z=1.74, p=.04\right)$. 
Table I. The results of song ratings on a 7-point scale (mean $\pm S D)$.

\begin{tabular}{|c|c|c|c|c|c|}
\hline Song & Song 1 & Song 2 & Song 3 & Song 4 & Song 5 \\
\hline & Adoration & Lost Shoal & $\begin{array}{l}\text { Give Me a Reason } \\
\text { to Forget }\end{array}$ & Onion & Listen to the Sea \\
\hline Preference & $5.39 \pm 1.21$ & $5.23 \pm 1.34$ & $4.51 \pm 1.35$ & $4.84 \pm 1.13$ & $5.39 \pm 1.06$ \\
\hline Familiarity & $5.74 \pm 1.34$ & $5.13 \pm 1.94$ & $3.39 \pm 1.90$ & $5.09 \pm 1.43$ & $6.51 \pm 0.82$ \\
\hline Urge to cry & $3.87 \pm 1.75$ & $4.10 \pm 1.57$ & $3.80 \pm 1.65$ & $3.83 \pm 1.57$ & $3.77 \pm 1.45$ \\
\hline
\end{tabular}

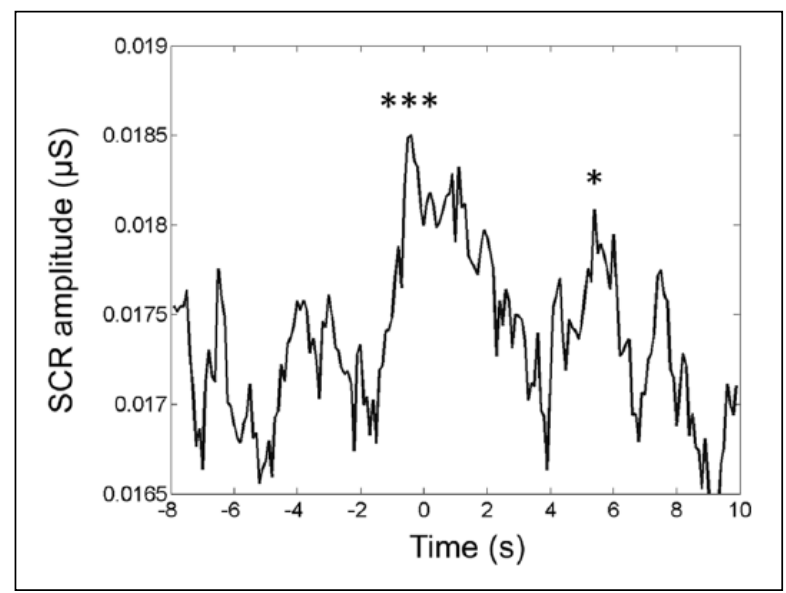

Figure I. The median curve of SCR amplitude around the entrance of choruses. The first downbeat of the chorus was set to $t=0 \mathrm{~s}$. The two peaks within this ROI were found significantly larger than the control data.

$* p<.05 ; * * * p<.001$

Figure $2 \mathrm{~A}$ shows the mean curves of finger temperature for the five songs. All curves are approximately U-shaped, with finger temperatures tending to decrease in the first part and increase in the second part. The onsets and ends of the first part and second part for each song are marked with an "•". The changes in individual finger temperature between these three extremes were calculated. The average temperature decrease over the first part of heartbreak songs was $0.259{ }^{\circ} \mathrm{C}$ and the average temperature increase over the second part was $0.177{ }^{\circ} \mathrm{C}$ (Figure 2B). One-tailed, one-sample $t$-tests of the finger changes revealed that the finger temperature significantly decreased over the first part $(t(38)=3.28, p=.002,95 \%$ CI $[-0.419$, $-0.099])$ and significantly increased over the second part $(t(38)=2.25, p=.03,95 \%$ CI $[0.018$, $0.335])$.

\section{Discussion}

On the basis of experimenter-selected, standardized musical excerpts, this study examined the time courses for listeners' arousal level and relaxation level during the presentations of popular heartbreak songs. Two particular time periods in these songs, the passage preceding the chorus 


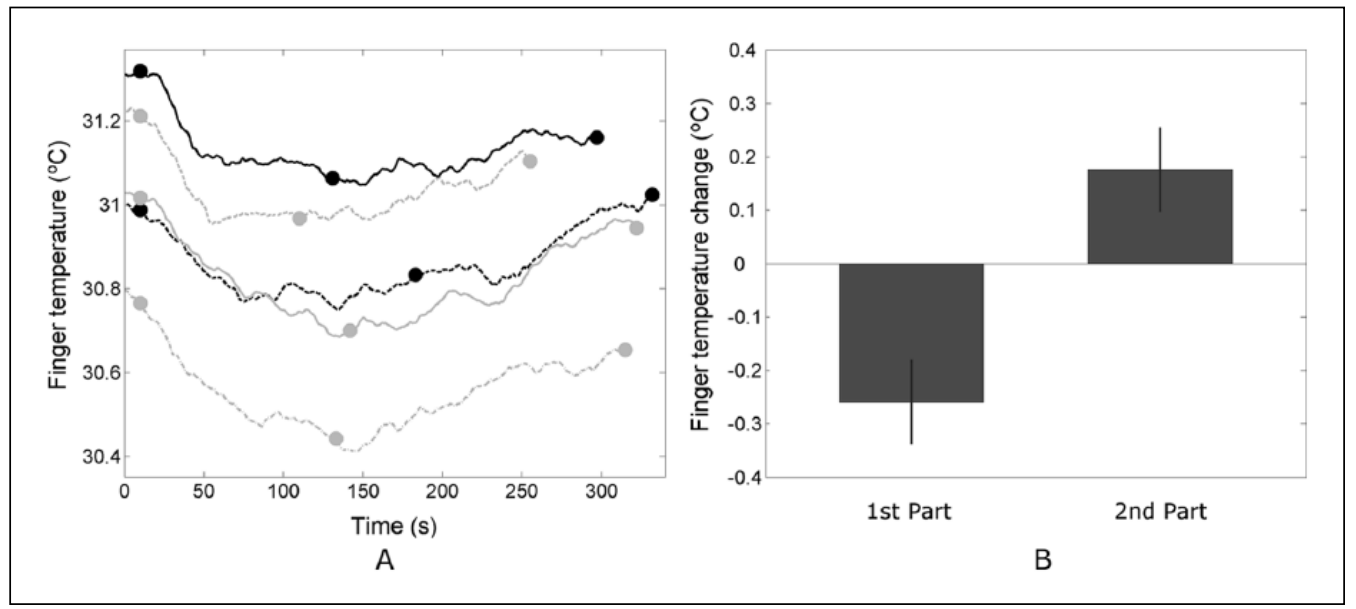

Figure 2. Listeners' finger temperature during song presentation. (A) The average curves of finger temperature for the five songs. All curves are approximately $U$-shaped. The end of the first chorus divides each song into two parts. The onsets and ends of the first part and second part for each song are marked with an "•". The finger temperature tended to decrease in the first part and to increase in the second part. (B) The temperature changes over the first part and the second part of these songs. Error bars represent standard error of means (SEM).

and the entrance of the chorus, were found to evoke significant SCRs. This result confirms the arousing effects of the chorus. The average finger temperature of participants was a U-shape curve for each song, suggesting an initial emotionally negative bias in listeners during its first part followed by relaxation during the second part. A closer look at the temperature data indicated that the cathartic effects of heartbreak songs were likely to manifest after the end of the first chorus. Our findings support the chorus as having a critical effect on the temporal dynamics of emotional experience in listeners.

The verse and chorus acquire their hierarchical importance and emotional significance by means of contrast. A key feature of the verse-chorus form is the contrast between the chorus and its preceding passage. This contrast partially explains why chorus entrances evoked significant SCRs. Musical characteristics of SCR-inducing or chill-inducing passages suggested in previous studies include: (1) an increase in volume, (2) a change in register, (3) harmonically and melodically peculiar progressions, (4) the entrance of a voice/instrument/choir/ orchestra, and (5) the beginning of a new section (Grewe, Kopiez, \& Altenmüller, 2009; Grewe et al., 2007a; Grewe, Nagel, Kopiez, \& Altenmüller, 2007b; Guhn et al., 2007; Koelsch, Kilches, Steinbeis, \& Schelinski, 2008). Because the entrance of the chorus is often accompanied by changes in register, tonality, musical material, and timbre (Capuzzo, 2009; Doll, 2011), it is not surprising to find that listeners' SCRs accumulated around the entrances of this new section.

Identification of the two significant peaks of SCR amplitude at the chorus entrance lends support to two closely related phases of a pleasurable listening experience: anticipatory "wanting" and hedonic "liking" of rewards. Brain-imaging studies have shown that pleasurable music activates listeners' reward system and serves as an abstract reward (Blood \& Zatorre, 2001; Menon \& Levitin, 2005). In a more recent experiment of music listening, Salimpoor et al. (2011) demonstrated that the "wanting" phase and the "liking" phase were associated 
with anatomically distinct activity in the reward system. In popular music, the chorus is used to mark the musical climax of a song and is usually listeners' most memorable and favorite element. In this sense, musical choruses may be thought of as "rewards" for listening. The first peak on the median curve of SCR amplitude shown in Figure 1 occurred immediately before the chorus and may reflect the elevated arousal associated with the feeling of "wanting". For the five songs used in this study, the passages immediately before the chorus were either a short verse-to-chorus transition or a pre-chorus. Both serve as aural foreplay and help increase emotional tension and punctuate the transition from verse to chorus (Davis, 1984; Summach, 2011). The second peak shown in Figure 1A occurred immediately after the entrance of the chorus and may reflect the elevated arousal associated with the feeling of "liking". Given that SCR onset occurs 1-3 seconds after the onset of a trigger event (Levinson \& Edelberg, 1985), a peak of the median curve of SCR amplitude was likely to be evoked by a musical event occurring approximately 2 seconds before this peak. Therefore, the musical events around $t=-2.4$ and $t=3.4$ should induce SCR amplitudes that were significantly larger than the control data. Although the use of skin conductance as the index of sympathetic arousal in this study did not allow examination of the important distinction between the intense feelings of "wanting" and "liking", this distinction is worth further brain-imaging experiments in future research.

All five heartbreak songs induced U-shape curves in the average finger temperature of listeners, which has been used as a physiological index of emotion valence (Hsu \& Lai, 2004; Krumhansl, 1997; Lai, 2004; Lundqvist et al., 2009; Nater et al., 2006; Rickard, 2004). This finding may shed new light on the temporal dynamics of music-evoked emotions. Although these emotions are presumed to unfold over time, empirical data of the dynamic emotion for specific musical forms are relatively scant. In the current experiment, the intro and the first verse-chorus progression of heartbreak songs seemed to intensify the negative emotions of listeners, as revealed in the significantly decreased finger temperature. Mechanisms underlying this phenomenon may include emotional contagion and semantic association (Fritz \& Koelsch, 2008; Juslin \& Vastfjall, 2008). The former is related to musically conveyed sadness in the intro and the first verse-chorus progression; the latter is likely due to the integration of lyrics and music in the first verse-chorus progression. Both behavioral (Ali \& Peynircioğlu, 2006) and brain-imaging (Brattico et al., 2011) experiments have demonstrated that lyrics intensify listeners' emotions in negatively valenced music.

Increasing finger temperature in listeners was observed during the second verse-chorus progression and thereafter. This finding is consistent with the observation that those who suffer from negative affect will seek out negatively valenced media to achieve some form of gratifying emotional response (Mares \& Cantor 1992; Nabi, Finnerty, Domschke, \& Hull, 2006). Several putative psychological mechanisms underlie this response. The first is the cathartic release often associated with Greek tragedy. This mechanism may allow listeners to "find an outlet" and release their negative emotions under the guidance of the first verse-chorus progression. As a result, they may attain a more relaxed state after the end of the first chorus. While the verse of a heartbreak song often depicts static scenes or the current status of an interpersonal relationship, the chorus often conveys the singer's inner sorrow or passions, thereby facilitating cathartic release in listeners (Tsai et al., in press). This hypothesis is supported by the venting of anger or sadness through the self-regulatory use of music that conveys these emotions (Arnett, 1991; Saarikallio, 2011).

The significantly increasing level of relaxation during the second part of a heartbreak song may also relate to a "mere exposure" effect, whereby any musical piece may be perceived as more pleasing over time due to increased exposure (Peretz, Gaudreau, \& Bonnel, 1998). Previous studies of exposure to music have found an inverted U-shaped relationship between 
how much a song is liked and the length/frequency of exposure (Brentar, Neuendorf, \& Armstrong, 1994; Szpunar, Schellenberg, \& Pliner, 2004). Witvliet and Vrana (2007) used musical stimuli conveying diverse emotional valences and arousal levels to examine the mere exposure effect. They found response polarization after repeated exposure, with negative-emotion-inducing music liked less and positive-emotion-inducing music liked more. Their experiment is relevant in terms of the sad musical stimuli used in the current study, but our data did not show response polarization while participants listened to the second or third choruses. Therefore, it is reasonable to speculate that the higher-level processing of heartbreak songs may play a role in the cathartic effects of this genre.

Schubert (1996) indicated that some listeners are able to deactivate displeasure in aesthetic contexts and thus enjoy the emotional arousal of sad music. A study on habitual music-listening behavior also revealed that arousing/intensifying specific emotions is one reason people listen to music (Thoma, Scholz, Ehlert, \& Nater, 2012). The shift from the contagion of negative emotion to the aesthetic evaluation that occurs while listening to a heartbreak song may be attributed to the musical manipulations in the second part of the song. The third choruses in 4 of the 5 songs used in this study manifest textual, dynamic, timbral, and tonal contrasts. Further, a bridge featuring skillful vocal expressions or an instrumental solo frequently precedes the third chorus. These musical characteristics may reorient listeners' attention away from the negatively valenced lyrics and toward evaluating the underlying aesthetics of the music.

Moreover, the different emotional responses to the two parts of a heartbreak song may also be related to two different emotion-regulation mechanisms: distancing and reinterpreting. Distancing takes a detached, third-person perspective to evaluating an emotional event. This strategy helps people analyze negative experiences adaptively (Kross \& Ayduk, 2009). When listening to a heartbreak song, emotional empathy may induce negative emotions during the first verse-chorus progression. Emotional empathy involves the embodied simulation based on a visceromotor representation of another's affective state (Schnell, Bluschke, Konradt, \& Walter, 2011; Shamay-Tsoory, Aharon-Peretz, \& Perry, 2009). In the second verse-chorus progression, the negative emotion conveyed by the song may be analyzed from a distanced perspective or cognitive empathy, defined as the cognitive inference of another person's affective state (Schnell et al., 2011; Shamay-Tsoory et al., 2009).

Reinterpreting is another emotion-regulation mechanism that may occur while listening to a heartbreak song. This mechanism involves adopting an altered perspective on the situational or contextual aspects of stimuli (Ochsner \& Gross, 2008). The current study argues that changes in musical aspects during the repetitions of the verse/chorus may facilitate regulation of listeners' emotions. The second verse-chorus progression in all of the five songs differs from the first verse-chorus progression in terms of higher rhythmic/textual activity. This musical feature may offer a fresh approach for listeners to the sadness and pain conveyed in the song. While elucidation of these putative mechanisms remains a task for future research, a comparison of emotion regulation with bibliotherapy may be helpful here. Bibliotherapy employs books as psychotherapeutic tools to promote psychological health (Hynes \& Hynes-Berry, 1986), with readers advancing through several stages including identification, catharsis, and insight (McKenna, Hevey, \& Martin, 2010; Shrodes, 1950). Listening to heartbreak songs may provide an experience similar to bibliotherapy. The initial presentation of the song verse facilitates listeners' identification with the song's emotional landscape, while the initial presentation of the song chorus gives vent to deeper, more ardent emotions. Note that slight but critical changes are often made to later repetitions of the verse and chorus in the song. In the second part of a verse-chorus song, skillful vocal/instrumental expressions may reorient listeners' attention toward evaluating the underlying aesthetics. Our results of listeners' U-shaped finger 
temperatures suggest that the reinterpretation of musical materials may facilitate adaptive reappraisal in listeners.

Two methodological issues related to the temporal dynamics of emotion must be highlighted with regard to this study. First, methods previously used in research to monitor the real-time status of musical emotions in listeners include asking listeners to press a button to indicate the onset of emotional chills (Grewe et al., 2007a, 2007b; Guhn et al., 2007; Salimpoor et al., 2009) and asking listeners to continuously respond in two-dimensional emotion-space (Bachorik et al., 2009; Schubert, 2004). The current study used objective physiological measures to reduce the potential confounding effects of secondary tasks. Participants did not indicate that the finger sensors prevented their enjoyment of the music. Second, this study relied on the formal structure of songs to confine the temporal ROI (around the entrance of the chorus) in statistical comparisons of physiological data. We suggest that the problem of multiple comparisons for time-series data may be circumvented when statistical analysis is guided by the a priori knowledge of the musical form, in which several sections are carefully arranged to promote listener's emotional experiences.

One limitation of this study is that although initial evidence of the arousing and cathartic effects of heartbreaking songs was found, this evidence does not discern between the discrete impacts of lyrics and music. Assessment of the discrete impacts of these two song elements awaits future study. A second limitation of this study is the limitation of stimuli to five heartbreak songs that are popular in Taiwan. Caution should be exercised in generalizing study findings to all verse-chorus songs. Future investigations need to examine whether listener's U-shaped finger temperature is also associated with verse-chorus songs that do not mention heartbreak. Further, the present study ignores individual participant differences in music listening and emotion regulation behavior. Lack of personality data prevents analysis of correlations between the physiological responses and the affective styles of participants. Research on individual differences is particularly important with regard to the therapeutic applications of heartbreak songs because the effects of emotion regulation vary across individuals and contexts (Schmidt, Tinti, Levine, \& Testa, 2010; Troy, Shallcross, \& Mauss, 2013).

In sum, this study explored the listening experiences of individuals with regard to popular heartbreak songs and related the time courses of participant arousal/emotion to the versechorus form. In agreement with the wanting-liking model for rewards, both the preparing passage immediately before the chorus and the entrance of the chorus evoked significant SCRs. Average finger temperature exhibited a U-shaped curve across each song. This may reflect an accumulation of negative emotions followed by a release, resolution, or regulation of negative emotions in listeners. The findings of this study suggest that the rewarding nature of the chorus, the cathartic effects of carefully arranged sections, and the reinterpretation of musical materials are all factors that underpin and extend the popularity of songs that convey emotions of sadness or pain. Our findings may also inform future studies of the benefits of closing the gap between physiology, psychology, and formal music analysis.

\section{Funding}

This work was financially supported by Ministry of Science and Technology (Taiwan) under Grant NSC 102-2420-H-002-006 and National Taiwan University (Taiwan) under Grant 102R892101.

\section{References}

Ali, S. O., \& Peynircioğlu, Z. F. (2006). Songs and emotions: Are lyrics and melodies equal partners? Psychology of Music, 34, 511-534. 
Arnett, J. (1991). Adolescents and heavy-metal music: From the mouths of metalheads. Youth $\mathcal{E}$ Society, 23, 76-98.

Azadeh, K., Jillian, F., Satyam, M., Gillian, K., \& Tom, C. (2011). Comparison of blood volume pulse and skin conductance responses to mental and affective stimuli at different anatomical sites. Physiological Measurement, 32, 1529.

Bachorik, J. P., Bangert, M., Loui, P., Larke, K., Berger, J., Rowe, R., \& Schlaug, G. (2009). Emotion in motion: Investigating the time-course of emotional judgments of musical stimuli. Music Perception, $26,355-364$.

Blain, S., Mihailidis, A., \& Chau, T. (2008). Assessing the potential of electrodermal activity as an alternative access pathway. Medical Engineering \& Physics, 30, 498-505.

Blain, S., Power, S. D., Sejdic, E., Mihailidis, A., \& Chau, T. (2010). A cardiorespiratory classifier of voluntary and involuntary electrodermal activity. BioMedical Engineering OnLine, 9, 11.

Blood, A. J., \& Zatorre, R. J. (2001). Intensely pleasurable responses to music correlate with activity in brain regions implicated with reward and emotion. Proceedings of the National Academy of Sciences, $98,11818-11823$.

Brattico, E., Alluri, V., Bogert, B., Jacobsen, T., Vartiainen, N., Nieminen, S., \& Tervaniemi, M. (2011). A functional MRI study of happy and sad emotions in music with and without lyrics. Frontiers in Psychology, 2, 308.

Brentar, J. E., Neuendorf, K. A., \& Armstrong, B. (1994). Exposure effects and affective responses to music. Communication Monographs, 61, 161-181.

Capuzzo, G. (2009). Sectional tonality and sectional centricity in rock music. Music Theory Spectrum, 31 , $157-174$.

Chanda, M. L., \& Levitin, D. J. (2013). The neurochemistry of music. Trends in Cognitive Sciences, 17(4), $179-193$.

Craig, D. G. (2005). An exploratory study of physiological changes during "chills" induced by music. Musicae Scientiae, 9, 273-287.

Davis, S. (1984). The craft of lyric writing. Cincinnati, OH: Writer's Digest Books.

Doll, C. (2011). Rockin' out: Expressive modulation in verse-chorus form. Music Theory Online 17(3). Retrieved from http://www.mtosmt.org/issues/mto.11.17.3/mto.11.17.3.doll.html

Fritz, T., \& Koelsch, S. (2008). The role of semantic association and emotional contagion for the induction of emotion with music. Behavioral and Brain Sciences, 31, 579-580.

Garrido, S., \& Schubert, E. (2011). Individual differences in the enjoyment of negative emotion in music: A literature review and experiment. Music Perception, 28, 279-295.

Grewe, O., Kopiez, R., \& Altenmüller, E. (2009). Chills as an indicator of individual emotional peaks. Annals of the New York Academy of Sciences, 1169, 351-354.

Grewe, O., Nagel, F., Kopiez, R., \& Altenmüller, E. (2007a). Emotions over time: Synchronicity and development of subjective, physiological, and facial affective reactions to music. Emotion, 7, 774-788.

Grewe, O., Nagel, F., Kopiez, R., \& Altenmüller, E. (2007b). Listening to music as a re-creative process: Physiological, psychological, and psychoacoustical correlates of chills and strong emotions. Music Perception, 24, 297-314.

Guhn, M., Hamm, A., \& Zentner, M. (2007). Physiological and musico-acoustic correlates of the chill response. Music Perception, 24, 473-484.

Hsu, W. C., \& Lai, H. L. (2004). Effects of music on major depression in psychiatric inpatients. Archives of Psychiatric Nursing, 18, 193-199.

Huron, D. (2011). Why is sad music pleasurable? A possible role for prolactin. Musicae Scientiae, 15, 146158.

Hynes, A. M., \& Hynes-Berry, M. (1986). Bibliotherapy - The interactive process: A handbook. St. Cloud, MN: North Star Press.

Juslin, P. N., \& Vastfjall, D. (2008). Emotional responses to music: The need to consider underlying mechanisms. Behavioral and Brain Sciences, 31, 559-575.

Kawakami, A., Furukawa, K., Katahira, K., \& Okanoya, K. (2013). Sad music induces pleasant emotion. Frontiers in Psychology, 4, 311. 
Khalfa, S., Isabelle, P., Jean-Pierre, B., \& Manon, R. (2002). Event-related skin conductance responses to musical emotions in humans. Neuroscience Letters, 328, 145-149.

Koelsch, S., Kilches, S., Steinbeis, N., \& Schelinski, S. (2008). Effects of unexpected chords and of performer's expression on brain responses and electrodermal activity. PLoS One, 3, e2631.

Kross, E., \& Ayduk, Ö. (2009). Boundary conditions and buffering effects: Does depressive symptomology moderate the effectiveness of distanced-analysis for facilitating adaptive self-reflection? Journal of Research in Personality, 43, 923-927.

Krumhansl, C. L. (1997). An exploratory study of musical emotions and psychophysiology. Canadian Journal of Experimental Psychology, 51, 336-353.

Lai, H. L. (2004). Music preference and relaxation in Taiwanese elderly people. Geriatric Nursing, 25, 286-291.

Lang, P. J., Greenwald, M. K., Bradley, M. M., \& Hamm, A. O. (1993). Looking at pictures: Affective, facial, visceral, and behavioral reactions. Psychophysiology, 30, 261-273.

Lee, C. J., Andrade, E. B., \& Palmer, S. E. (2013). Interpersonal relationships and preferences for moodcongruency in aesthetic experiences. Journal of Consumer Research, 40, 382-391.

Levinson, D. F., \& Edelberg, R. (1985). Scoring criteria for response latency and habituation in electrodermal research: A critique. Psychophysiology, 22, 417-426.

Lundqvist, L. O., Carlsson, F., Hilmersson, P., \& Juslin, P. N. (2009). Emotional responses to music: Experience, expression, and physiology. Psychology of Music, 37, 61-90.

Mares, M. L., \& Cantor, J. (1992). Elderly viewers' responses to televised portrayals of old age: Empathy and mood management versus social comparison. Communication Research, 19, 459-478.

Mcfarland, R. A. (1985). Relationship of skin temperature-changes to the emotions accompanying music. Biofeedback and Self-Regulation, 10, 255-267.

McKenna, G., Hevey, D., \& Martin, E. (2010). Patients' and providers' perspectives on bibliotherapy in primary care. Clinical Psychology and Psychotherapy, 17, 497-509.

Menon, V., \& Levitin, D. J. (2005). The rewards of music listening: Response and physiological connectivity of the mesolimbic system. Neuroimage, 28, 175-184.

Nabi, R., Finnerty, K., Domschke, T., \& Hull, S. J. (2006). Does misery love company? Exploring the therapeutic effects of TV viewing on regretted experiences. Journal of Communication, 56, 689-706.

Nater, U. M., Abbruzzese, E., Krebs, M., \& Ehlert, U. (2006). Sex differences in emotional and psychophysiological responses to musical stimuli. International Journal of Psychophysiology, 62, 300-308.

Ochsner, K. N., \& Gross, J. J. (2008). Cognitive emotion regulation: Insights from social, cognitive, affective neuroscience. Current Directions in Psychological Science, 17, 153-158.

Panksepp, J., \& Bernatzky, G. (2002). Emotional sounds and the brain: The neuro-affective foundations of musical appreciation. Behavioural Processes, 60, 133-155.

Penzien, D. B., \& Holroyd, K. A. (1994) Psychosocial interventions in the management of recurrent headache disorders 2: Description of treatment techniques. Behavioral Medicine, 20, 64-73.

Peretz, I., Gaudreau, D., \& Bonnel, A. M. (1998). Exposure effects on music preference and recognition. Memory \& Cognition, 26, 884-902.

Rickard, N. S. (2004). Intense emotional responses to music: A test of the physiological arousal hypothesis. Psychology of Music, 32, 371-388.

Rolison, J. J., \& Edworthy, J. (2012). The role of formal structure in liking for popular music. Music Perception, 29, 269-284.

Saarikallio, S. (2011). Music as emotional self-regulation throughout adulthood. Psychology of Music, 39 , $307-327$.

Salimpoor, V. N., Benovoy, M., Larcher, K., Dagher, A., \& Zatorre, R. J. (2011). Anatomically distinct dopamine release during anticipation and experience of peak emotion to music. Nature Neuroscience, $14,257-262$.

Salimpoor, V. N., Benovoy, M., Longo, G., Cooperstock, J. R., \& Zatorre, R. J. (2009). The rewarding aspects of music listening are related to degree of emotional arousal. PLoS One, 4, e7487.

Schnell, K., Bluschke, S., Konradt, B., \& Walter, H. (2011). Functional relations of empathy and mentalizing: An fMRI study on the neural basis of cognitive empathy. Neuroimage, 54, 1743-1754. 
Schmidt, S., Tinti, C., Levine, L. J., \& Testa, S. (2010). Appraisals, emotions and emotion regulation: An integrative approach. Motivation and Emotion, 34, 63-72.

Schubert, E. (1996). Enjoyment of negative emotions in music: An associative network explanation. Psychology of Music, 24, 18-28.

Schubert, E. (2004). Modeling perceived emotion with continuous musical features. Music Perception, 21, 561-585.

Shamay-Tsoory, S. G., Aharon-Peretz, J., \& Perry, D. (2009). Two systems for empathy: A double dissociation between emotional and cognitive empathy in inferior frontal gyrus versus ventromedial prefrontal lesions. Brain, 132, 617-627.

Shaw, P., \& Su, C. S. (2001). Disclosure of mist of romantic love in Taiwan's popular music: 1989-1998 [in Chinese]. Mass Communication Research, 70, 167-195.

Shin, E. H., \& Oh, J. H. (2002). Changing patterns of social network structure in composer-singer relationships: A case study of the Korean popular music industry, 1927-1997. East Asia, 20, 24-53.

Shrodes, C. (1950). Bibliotherapy: A theoretical and clinical-experimental study (Unpublished doctoral dissertation). University of California, Berkeley, CA.

Stephenson, K. (2002). What to listen for in rock: A stylistic analysis. New Haven, CT: Yale University Press.

Stevens, C. S. (2007). Japanese popular music: Culture, authenticity and power. London, UK: Routledge.

Summach, J. (2011). The structure, function, and genesis of the prechorus. Music Theory Online 17(3). Retrieved from http://www.mtosmt.org/issues/mto.11.17.3/mto.11.17.3.summach.html

Szpunar, K. K., Schellenberg, E. G., \& Pliner, P. (2004). Liking and memory for musical stimuli as a function of exposure. Journal of Experimental Psychology: Learning Memory and Cognition, 30, 370-381.

Thoma, M. V., Scholz, U., Ehlert, U., \& Nater, U. M. (2012). Listening to music and physiological and psychological functioning: The mediating role of emotion regulation and stress reactivity. Psychology $\mathcal{E}$ Health, 27, 227-241.

Troy, A. S., Shallcross, A. J., \& Mauss, I. B. (2013). A person-by-situation approach to emotion regulation: Cognitive reappraisal can either help or hurt, depending on the context. Psychological Science, $24,2505-2514$.

Tsai, C. G., Chen, R. S., \& Yu, S. P. (in press). Analyzing the verse-chorus form: Schema shifts and musical rewards in lyrical-slow songs [in Chinese]. Research in Applied Psychology.

Wallin, B. G. (1981). Sympathetic nerve activity underlying electrodermal and cardiovascular reactions in man. Psychophysiology, 18, 470-476.

Wilhelm, K., Gillis, I., Schubert, E., \& Whittle, E. (2013). On a blue note: Depressed peoples' reasons for listening to music. Music and Medicine, 5, 76-83.

Witvliet, C. V. O., \& Vrana, S. R. (2007). Play it again Sam: Repeated exposure to emotionally evocative music polarises liking and smiling responses, and influences other affective reports, facial EMG, and heart rate. Cognition and Emotion, 21, 3-25. 